Verfälschung des Jodkaliums mit Bromkalium. 315

\title{
Wiedergewinnung des Jods aus den künstlichen Jodbädern.
}

Die häufige Anwendung des Jodkaliums in Frankreich hat darauf aufmerksam gemacht. - Die Trennung geschieht nach Labiche und $\mathrm{Chantrel}$, indem durch Chlor eine Zerlegung statt findet, und demnächst durch Stärkemehl Jod gefesselt wird, unter stetem Umrühren. Der Bodensatz wird mit wenigem Wasser angemengt und demnächst so lange schweflige Säure hinzugeleitet, bis eine Entfärbung statt fand. - Es wird Hydrojod- und Schwefelsäure gebildet, welche später nach gehörigem Auswaschen des Sedimentes mil Kali behandelt wird, wobei sich Jodkalium und schwefelsaures Kali bildet (auch etwas Schwefelniederschlag). Man verdunstet zur Syrupsconsistenz, und behandelt den Rückstand mit Schwefelsäure und Mangansuperoxyd, um Jod zu gewinnen. Ein anderes Verfahren das Jod zu gewinnen wird darin vorgeschlagen, dass man Jodamylum mit Aetzkalk vermengt und nun unter Zusatz von Wasser eine pastaartige Kalkmilch davon anfertigt. Es wird nun die gemengte Masse in eisernen Gefässen eingeäschert und ähnlich mil Schwefelsäure und Mangansuperoxyd behandelt, um Jod zu gewinnen. - Es beruhet das Verfahren (?) auf einer Eigenschaft des Jods, auch mit Kohle eine Verbindung einzugehen. (Journ. de Pharm. et de Chim. Avril 1846. p. 267 etc.)

Wilting.

\section{Verfälschung des Jodkaliums mit Bromkalium.}

Wenn eine Lösung des Jodkaliums mit schwefelsaurem Kupferoxyd behandelt wird, so bildet sich $\mathrm{Cu}^{3}$ $\mathbf{J}^{2}$, und die Hälfte des Jods bleibt trotz einem Ueberschuss des Kupfersalzes in der Flüssigkeit. Duflos zeigte, dass alles Jod gefällt werden könne, wenn ein Ueberschuss von $\mathrm{SO}^{2}$ hinzugesetzt wird, wodurch sich Kupferoxydul bildet, während $\mathrm{SO}^{3}$ sich erzeugt. Mit dem Chlorkalium ist es nicht der Fall und der neueren Untersuchung von Personne nach auch nicht mit dem Bromkalium. Die Gegenwart des Broms ergiebt sich, wenn nach der Trennung des $\mathrm{Ca}^{2} \mathbf{J}^{2}$, die Flüssigkeit mit Aether behandelt und wie bekannt, ferner verfahren wird. - (Journ. de Pharm. et de Chim. Mai 1846. p. 356.) Witting.

\section{Aetzbaryt.}

Als ein sehr einfaches und wenig kostspieliges Vero fahren zur Darstellung von Aetzbaryı empfiehlt Riegel 
eine concentrirte Lösung von Schwefelbaryum mit einer hinreichenden Mlenge von fein gepulvertem Manganhyperoxyd zu erhitzen, bis Reagentien keinen Schwefelwasserstoff in der Fliussigkeit mehr anzeigen, und möglichst schnell zu filtriren; aus der heissen concentrirlen Lösung schiessen beim Erkalten farblos durchsichtige, vierseitige und gedrückte sechsseitige Saulen mit 4 Flächen zugespitzt von Barythydrat mit Krystallwasser an. Die Bildung von schwefligsaurem Baryt nahm R i e gel nicht wahr. Beim Vermischen der mil hinreichendem Mangansuperoxyd erhitzten Schwefelbaryumlösung mit ein Paar Tropfen Bleiessig, erhielt er einen schön ziegelrothen Niederschlag, den er später nicht wieder erhalten konnte und desshalb die Aufmerksamkeit der diese Arbeit Vornehmenden darauf zu lenken wünscht. (Jahrb. f. prakt. Pharm. 12. 2. 106.) B.

\section{Irystallisirtes Schwefelcalcium.}

Ein solches Präparat erhielt Riegel, als er 1 Theil Kalkhydrat mit $2 \frac{1}{2}$ Theil Schwefel und 16 Theilen Wasser anhaltend kochte. filtrirte und bei Seite stellte, wo aus der braungelben Flüssigkeit beim Erkalten rothgelbe, nadelförmige Prismen anschossen, welche nach $\mathrm{H}$ ers ch el $\mathrm{CaS}^{2}+3 \mathrm{Aq}$, folglich doppelt Schwefelcalcium mit $3 \mathrm{At}$. Wasser sind. Die Krystalle zersetzten sich schnell an der Luft.

Als die beste Methode der Darstellung des Schwefelcalciums hält Riegel die von Liebig, wenn man ein Gemenge von 4 Theilen gebrannten Gyps, 1 Theil Kohlenpulver und $1_{\frac{1}{2}}$ Theil Roggenmehl mit Wasser zu einem Teige knetet, daraus Kugeln formt, und diese, nach dem Austrocknen zwischen Kohlen geschichtet bei heller Rothglühhitze durchglüht. (Jahrb. für prakt. Pharm. 12. 2. 104.) $B$.

\section{Ausbeute an Gold und Platina in Russland im Jahre 1845.}

Die zweite Hälfte des Jahres 1845 hat aus den Kronund Privat-Bergwerken des Uralgebirges nachstehende Gold - und Platina-Ausbeute gegeben: Die Krone bezog an Gold: 70 Pud 13 Pfd. 36 Sololnik. Privatleute: 190 Pud 7 Pfd. 51 Solotnik. Platina wurde von beiden Theilen bezogen: 11 Pud $35 \mathrm{Pfd}$. 49 Solotnik. Der altajsche Bergwerksbezirk, sich zwischen Ost - und West-Sibirien ausdehnend, gab beiden Theilen eine Goldausbeute von 